\title{
Role of glucagon suppression on gluconeogenesis during insulin treatment of the conscious diabetic dog
}

\author{
R. W. Stevenson ${ }^{1}$, P.E. Williams ${ }^{2}$ and A. D. Cherrington ${ }^{2}$ \\ ${ }^{1}$ Department of Metabolic Disease, Pfizer Central Research, Groton, Connecticut, and \\ ${ }^{2}$ Department of Molecular Physiology and Biophysics, Vanderbilt University Medical School, Nashville, Tennesee, USA
}

\begin{abstract}
Summary. In seven insulin-deficient $(<3 \mathrm{mU} / \mathrm{l})$ pancreatectomised dogs, the direct and glucagon-related indirect effects of intraportal insulin infusion $(350 \mu \mathrm{U} / \mathrm{kg}$-min; $12 \pm 1 \mathrm{mU} / 1)$ on glucose production were determined. Insulin was infused for 300 min during which time the plasma glucagon concentration was allowed to fall $(314 \pm 94$ to $180 \pm 63 \mathrm{ng} / 1)$ for $150 \mathrm{~min}$ before being replaced by an infusion intraportally at $2.6 \mathrm{ng} / \mathrm{kg}-\min (323 \pm 61 \mathrm{ng} / \mathrm{l})$ for the remaining $150 \mathrm{~min}$. Glucose production and gluconeogenesis were determined using arterio-venous difference and tracer techniques. Insulin infusion shut off net hepatic glucose output and caused the plasma glucose, blood glycerol and plasma non-esterified fatty acid levels to fall. It caused the hepatic fractional extraction of alanine $(0.41 \pm 0.10$ to $0.21 \pm 0.06)$ and lactate $(0.32 \pm 0.09$ to $0.04 \pm 0.03)$ to fall which increased their concentrations. When glucagon was replaced, all of these
\end{abstract}

changes were fully or partly reversed with the exception of the changes in glycerol and nonesterified fatty acids. Indeed, $70 \%$ of the fall in hepatic glucose production and virtually $100 \%$ of the changes in lactate and alanine metabolism produced by basal insulin infusion were mediated by a fall in glucagon. However, the fall in hepatic uptake of glycerol was unaffected by changes in glucagon and thus gluconeogenesis from this substrate was inhibited by insulin per se probably as a result of reduced lipolysis. The latter effect of insulin may explain the incomplete restoration of hepatic glucose production when hyperglucagonaemia was re-established during insulin infusion.

Key words: Diabetes, insulin, glucagon, glycogenolysis, gluconeogenesis, dog.
Fasting hyperglycaemia is associated with insulin-deficient diabetes and is accompanied by inappropriately raised plasma glucagon concentrations [1-4]. However, insulin treatment can reduce or even normalise glucagon levels in the diabetic dog $[4,5]$ and man $[6,7]$. Since both elevations in plasma insulin [8] and reductions in plasma glucagon [9] can reduce hepatic glucose production and gluconeogenesis, the aim of the present study was to determine the relative roles of the changes in insulin and glucagon which result from insulin infusion in reducing the hyperglycaemia and elevated gluconeogenesis apparent in overnight-fasted diabetic (pancreatectomised) dogs. This was accomplished by administering insulin alone via the portal circulation at a low infusion rate then re-establishing the starting glucagon levels in the second half of the study by intraportal infusion of glucagon coincident with the insulin infusion. Since the dogs were prepared with indwelling catheters in the left common hepatic vein, the portal vein and in the femoral artery, net hepatic balances of glucose and gluconeogenic substrates could be calculated using the arteriovenous difference technique.

\section{Materials and methods}

\section{Animals and surgical procedures}

Eleven mongrel dogs (15-23 kg) of either sex were fed a normal diet (Kal Kan meat and Wayne Dog Chow, Wayne Meat Ration, Allied Mills, Inc., Chicago, Ill, USA; 31\% protein, 52\% carbohydrate, $11 \%$ fat and 6\% fiber based on dry weight) for 2-3 weeks prior to their use. Sixteen to seventeen days before each experiment a laparotomy was performed under general anesthesia (sodium pentobarbital$25 \mathrm{mg} / \mathrm{kg}$ ) and a pancreatectomy was performed as described elsewhere [10] with the exception that no pancreatic autograft was created. At the same time, silastic catheters were inserted into a splenic vein, the portal vein, the left common hepatic vein and a femoral artery. The tip of the portal vein catheter was placed $2 \mathrm{~cm}$ from the point at which the vessel enters the liver, and the tip of the hepatic vein catheter was placed $1 \mathrm{~cm}$ inside the left common hepatic vein. After the catheters were inserted they were filled with saline containing heparin $(200 \mathrm{U} / \mathrm{ml}$, Abbott Laboratories, North Chicago, Ill, USA), and their free ends were knotted and placed in subcutaneous pockets so that complete closure of the incisions was possible. Postoperatively the animals were fed a normal diet (as above) to which exocrine pancreatic enzymes (5 tablets Pancrease) and cimetidine $(300 \mathrm{mg}$ ) were added to compensate for altered exocrine pancreatic function. Insulin was administered approximately $30 \mathrm{~min}$ before feeding (once each day) and the dose (approximately $8 \mathrm{U}$ regular, $24 \mathrm{U}$ NPH insulin) was adjusted to prevent glucosuria and to keep 
the blood sugar below $10 \mathrm{mmol} / \mathrm{l}$. Two weeks after surgery blood was withdrawn to determine the leukocyte count and hematocrit of the animal. Only animals which had: (1) a leukocyte count below $16,000 \mathrm{~mm}^{3}$, (2) a hematocrit above $38 \%$, (3) a good appetite (consuming all of the daily ration), and (4) normal stools, were used.

The last injections of NPH and regular insulin were administered 48 and $18 \mathrm{~h}$, respectively, before each study. On the day of the experiment, the free ends of the catheters were removed from the subcutaneous pockets through small skin incisions made under local anesthesia (2\% Lidocaine, Astro Pharmaceutical Prod., Inc., Worchester, Md, USA). The contents of each catheter were aspirated and the catheters were flushed with fresh saline before use. The splenic catheter was used for insulin and glucagon infusion and the remaining catheters were used for blood sampling. Angiocaths (20-gauge, Deseret Medical, Inc., Parke Davis and Co., Sandy, Utah, USA) were inserted percutaneously and into a cephalic vein for infusion of $3-{ }^{3} \mathrm{H}$-glucose, $\mathrm{U}_{-1}^{14} \mathrm{C}$-alanine and indocyanine green. After completion of these procedures, each dog was allowed to stand calmly in a Pavlov harness for $20-30 \mathrm{~min}$ prior to the start of the experiment. Following all experiments, an autopsy was performed and the position of the catheters was confirmed.

\section{Experimental design}

Each experiment consisted of an $80 \mathrm{~min}(-120$ to $-40 \mathrm{~min})$ tracer equilibration period, a control period ( -40 to $0 \mathrm{~min}$ ), and a test period (0-300 min). The primed $(42 \mu \mathrm{Ci})$ constant infusion of $3{ }^{3} \mathrm{H}$-glucose $(0.36 \mu \mathrm{Ci} / \mathrm{min})$ and the constant infusion of $\mathrm{U}^{14} \mathrm{C}$-alanine $\left(0.05 \mu \mathrm{Ci} \cdot \mathrm{kg}^{-1} \cdot \mathrm{min}^{-1}\right)$ were started at $-120 \mathrm{~min}$ and continued throughout the study. In the test period insulin was infused $\left(350 \mu \mathrm{U} \cdot \mathrm{kg}^{-1} \cdot \mathrm{min}^{-1}\right)$ into the portal circulation and plasma glucagon was allowed to fall for $150 \mathrm{~min}$ before being replaced by intraportal infusion at $2.6 \mathrm{ng} \cdot \mathrm{kg}^{-1} \cdot \mathrm{min}^{-1}$ for the remaining $150 \mathrm{~min}$ $(150-300 \mathrm{~min})$. Both hormones were infused in a vehicle consisting of $0.9 \%$ saline and $3 \%(\mathrm{v} / \mathrm{v})$ of the dog's own plasma. In four of the dogs, the study was terminated at $150 \mathrm{~min}$ and samples of liver were taken and snap-frozen in liquid nitrogen for subsequent analysis of cold and radioactive $\left({ }^{3} \mathrm{H}\right.$ and $\left.{ }^{14} \mathrm{C}\right)$ glycogen by the method of Chan and Exton [25].

\section{Processing of blood samples}

Blood samples were drawn every $10 \mathrm{~min}$ during the control period and every $15 \mathrm{~min}$ thereafter. For the measurement of intermediary metabolites, $1 \mathrm{ml}$ of whole blood was added to $3 \mathrm{ml}$ chilled $4 \%(\mathrm{w} / \mathrm{v})$ perchloric acid. These samples were then centrifuged for $10 \mathrm{~min}$ at $10.000 \mathrm{~g}$ and the supernatant was stored at $-70^{\circ} \mathrm{C}$ for subsequent assays. Lactate and glycerol were measured as described elsewhere [38]. Plasma non-esterified fatty acids were assayed by the method of Ho [39].

It should be noted that the arterial and portal blood samples were collected simultaneously, approximately $30 \mathrm{~s}$ prior to collection of the hepatic venous samples. This was done in an attempt to compensate for the time required for glucose to pass through the liver [12] and thus allow accurate estimates of hepatic balance to be made even under non steady-state conditions. The ${ }^{14} \mathrm{C}$ - and ${ }^{3} \mathrm{H}$-glucose in plasma samples were determined by previously described techniques [13] and established liquid scintillation counting procedures. Plasma glucose concentrations were determined by the glucose oxidase method in a Beckman glucose analyser (Beckman Instruments, Inc., Fullerton, Calif, USA). Plasma ${ }^{14} \mathrm{C}$-alanine and ${ }^{14} \mathrm{C}$-lactate specific activities were determined using a short-column, ion-exchange chromatographic system, which has been previously described [14].

Immunoreactive glucagon was assayed (in plasma samples to which $500 \mathrm{~K}$. I. U. of Trasylol had been added) with $30 \mathrm{~K}$ antiserum [15]. The inter-assay coefficient of variation was $8 \%$. Immunoreactive insulin was measured by the Sephadex (Pharmacia Fine Chemicals, Piscataway, NJ, USA) bound-antibody procedure [16]. The inter-assay coefficient of variation was $11 \%$.

\section{Materials}

$3-{ }^{3} \mathrm{H}$-glucose $(11.5 \mathrm{mCi} / \mathrm{mmol}$ ) (New England Nuclear, Boston, Mass, USA) was used as the glucose tracer and $U-{ }^{14} \mathrm{C}$-alanine $(176 \mathrm{mCi} / \mathrm{mmol}$ ) (New England Nuclear) was used as the labelled gluconeogenic precursor. Glucagon and porcine insulin for infusion were purchased from Eli Lilly and Co. (Indianapolis, Ind, USA); Phadebas Insulin Radioimmunoassay kit was obtained from Pharmacia Fine Chemicals; and Trasylol was purchased from FBA Pharmaceuticals, Inc. (New York, NY, USA). Glucagon $30 \mathrm{~K}$ antiserum was obtained from the University of Texas Southwestern Medical School (Dallas, Texas, USA); and the standard glucagon and ${ }^{125} \mathrm{I}$ glucagon were bought from Novo Research Institute (Copenhagen, Denmark). All hormone solutions were prepared with normal saline containing $3 \%(\mathrm{v} / \mathrm{v})$ of the dog's own plasma to prevent adsorption to tubing and glassware. The $3-{ }^{3} \mathrm{H}$-glucose solution contained glucose at a final concentration of $1 \mathrm{mg} / \mathrm{ml}$.

\section{Tracer methods and calculations}

The rates of endogenous glucose production (rate of appearance-Ra) and utilisation (rate of disappearance) were determined by a modification of the method of Wall et al. [17] as simplified by DeBodo et al. [18] and as previously outlined [19]. Gluconeogenesis was assessed with a double isotope technique described elsewhere [20]. This technique involves the simultaneous infusion of two tracers, U${ }^{14} \mathrm{C}$-alanine to provide labelled substrate for the gluconeogenic pathway and $3-{ }^{3} \mathrm{H}$-glucose to measure glucose production. It is possible to use $3-{ }^{3} \mathrm{H}$-glucose to trace ${ }^{14} \mathrm{C}$-glucose production, just as it can be used to trace unlabelled glucose production. The only change required in the equation of DeBodo et al. [18] is replacement of the glucose concentration $(\mu \mathrm{mol} / \mathrm{ml})$ with the ${ }^{14} \mathrm{C}$-glucose "concentration" $(\mathrm{dpm} / \mathrm{ml})$. The production rate thus calculated has the units of $\mathrm{dpm} / \mathrm{min}$ and represents the whole body production rate of ${ }^{14} \mathrm{C}$-glucose. The hepatic ${ }^{14} \mathrm{C}$-glucose production rate can be simultaneously obtained with an arteriovenous difference technique [20].

Once the ${ }^{14} \mathrm{C}$-glucose production rate is determined, the rate of ${ }^{14} \mathrm{C}$-alanine conversion to ${ }^{14} \mathrm{C}$-glucose can be calculated by dividing the production rate of ${ }^{14} \mathrm{C}$-glucose $(\mathrm{dpm} / \mathrm{min})$ by the gluconeogenic precursor specific activity $(\mathrm{dpm} / \mu \mathrm{mol})$. The gluconeogenic specific activity is calculated from $\frac{0.28 \mathrm{~A}^{\prime}+0.72 \mathrm{P}^{\prime}}{0.28 \mathrm{~A}+0.72 \mathrm{P}}$ where $\mathrm{A}$ and $\mathrm{P}$ are the alanine concentrations $(\mu \mathrm{mol} / \mathrm{ml})$ in the artery and portal vein respectively and $A^{\prime}$ and $\mathrm{P}^{\prime}$ are the ${ }^{14} \mathrm{C}$-alanine concentrations $(\mathrm{dpm} / \mathrm{ml})$ in these vessels. The proportion of the hepatic blood supply provided by the hepatic artery was assumed to be $28 \%$ based on a compilation by Greenway and Stark [24] of data from many sources. Although U${ }^{14} \mathrm{C}$-alanine was infused in the present study, labelled lactate accumulated, presumably as a result of interconversion of the two molecules and of Cori cycle activity. However, the percentage change in the conversion of ${ }^{14} \mathrm{C}$-alanine to ${ }^{14} \mathrm{C}$-glucose or ${ }^{14} \mathrm{C}$-alanine plus ${ }^{14} \mathrm{C}$ lactate to ${ }^{14} \mathrm{C}$-glucose over the course of the experiment were virtually identical (data not shown) thus only ${ }^{14} \mathrm{C}$-alanine was used in the calculations. The results are expressed as the percentage change from control conversion rates because, as discussed elsewhere [21], the absolute rate of gluconeogenic conversion cannot be determined since dilution of the gluconeogenic precursor specific activity occurs within the hepatocyte to an extent which cannot be estimated accurately without performance of a separate experiment as described by Hetenyi [22]. The present method thus provides only an index of gluconeogenesis, the usefulness of which lies not in its absolute value, but in its alteration with time. The reliability of the index depends on the validity of the assumption that dilution of the labelled gluconeogenic precursors within the liver cell changes little during the course of the experiments. Since the dilution factor varied little in normal dogs, insulin-deprived diabetic dogs, long-term fasted dogs and methylprednisolone-treated dogs [22], it seems reasonable to assume that the dilution factor will change little in the present study.

Net hepatic balance for unlabelled glucose, unlabelled alanine, non-esterified fatty aids (NEFA) glycerol and lactate, as well as plas- 
ma ${ }^{3} \mathrm{H}$-3-glucose, ${ }^{14} \mathrm{C}$-glucose, and ${ }^{14} \mathrm{C}$-alanine, were determined by the formula $((0.28 \mathrm{~A}+0.72 \mathrm{P})-\mathrm{H}) \times \mathrm{HF}$ where $\mathrm{A}$ is the arterial concentration, $P$ is the portal vein concentration, $H$ is the hepatic vein concentration and HF is hepatic flow (blood or plasma) as determined by indocyanine green according to the method of Leevy et al. [23]. It should be noted that the use of plasma values of alanine and glucose for net balance calculation leads to underestimates of approximately 10 and $15 \%$ respectively. The advantages to using plasma values, however, are that the life of the ion exchange resin used for the isolation of alanine is prolonged, thus reducing cost, and multiple (five) determinations of the A-V difference for glucose can be made (only $10 \lambda$ pf plasma are required for each measurement) thereby increasing accuracy. To circumvent the underestimate in the case of hepatic glucose balance (but not ${ }^{3} \mathrm{H}-3$-glucose balance) the plasma glucose values were converted to whole blood glucose using a 0.73 correction factor determined earlier by comparing plasma values determined on the Beckman glucose analyser to blood values measured with a technicon autoanalyser.

The fractional extraction of substrates by the liver was determined using the formula $((0.28 \mathrm{~A}+0.72 \mathrm{P})-\mathrm{H}) /(0.28 \mathrm{~A}+0.72 \mathrm{P})$.

Unidirectional uptake of glucose by the liver was calculated from:

net hepatic uptake of ${ }^{3} \mathrm{H}-3$-glucose (dpm/kg-min)

S.A. of ${ }^{3} \mathrm{H}$-3-glucose $(\mathrm{dpm} / \mu \mathrm{mol})$

where S.A. is the specific activity of ${ }^{3} \mathrm{H}-3$-glucose in blood entering the liver. This calculation assumes that the ${ }^{3} \mathrm{H}$-glucose cannot come out of the liver once it has undergone a committed reaction. Since in the glucagon replacement period the liver produced ${ }^{3} \mathrm{H}$-glucose, the approach could not be used at that time.

Non-hepatic (peripheral) glucose uptake (PGU) was calculated independently from the tracer data using the equation, $P G U=N H G O-p V \frac{\Delta}{\Delta}$, where NHGO is net hepatic glucose output as assessed by the arteriovenous difference technique, $p$ is the distribution constant $(0.65), \mathrm{V}$ is the volume of distribution $(0.22 \times$ body weight $), \mathrm{c}$ is the cold glucose concentration $(\mu \mathrm{mol} / \mathrm{ml})$, and $\mathrm{t}$ is time (min).

\section{Statistical analysis}

Statistics were performed using the paired Student's t-test to compare data from the insulin infusion period to pre-infusion values.

\section{Results}

\section{Plasma insulin and glucagon levels}

Intraportal infusion of insulin at $350 \mu \mathrm{U} / \mathrm{kg}$-min caused the arterial plasma insulin concentration to rise $(p<0.05)$ from $3 \pm 1$ (lowest limit of sensitivity of insulin radioimmunoassay) to $12 \pm 1 \mathrm{mU} / 1$ (Fig. 1). The plasma glucagon level fell $(p<0.05)$ in response to the insulin infusion from $314 \pm 94$ to $180 \pm 63 \mathrm{ng} / \mathrm{l}$ by $150 \mathrm{~min}$ and was then raised to $323 \pm 61 \mathrm{ng} / 1$ for the remaining $150 \mathrm{~min}$ as a result of the intraportal glucagon infusion (2.6 $\mathrm{ng} / \mathrm{kg}$-min).

\section{Plasma glucose and glucose turnover}

After $150 \mathrm{~min}$ of insulin infusion the plasma glucose had fallen $(p<0.05)$ from $24.7 \pm 2.3$ to $14.1 \pm$ $1.2 \mathrm{mmol} / 1$ but it increased to $16.2 \pm 1.0 \mathrm{mmol} / 1$ when glucagon was replaced (Fig. 2). Net hepatic glucose output (estimated by the A-V difference technique us-

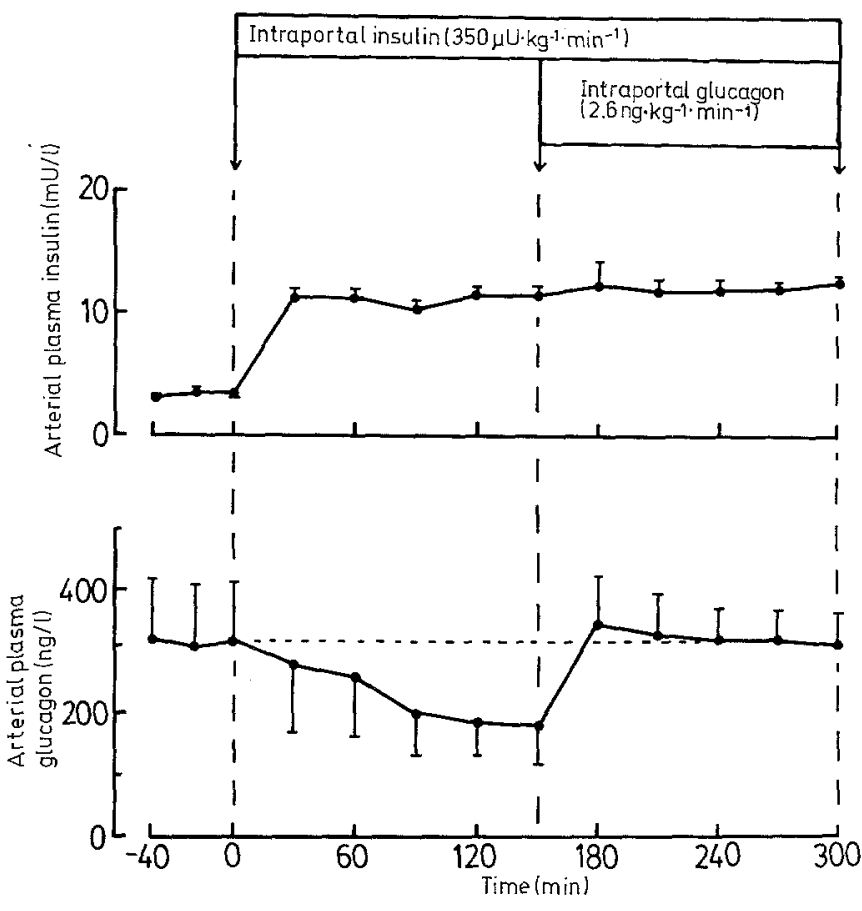

Fig. 1. Arterial plasma insulin and glucagon concentrations in 7 pancreatectomised dogs during intraportal insulin infusion $\left(350 \mu \mathrm{U} \cdot \mathrm{kg}^{-1} \cdot \mathrm{min}^{-1} ; 0-300 \mathrm{~min}\right)$, before $(0-150 \mathrm{~min})$ and during $(150-300 \mathrm{~min})$ intraportal replacement of glucagon at $2.6 \mathrm{ng} \cdot \mathrm{kg}^{-1}$. $\mathrm{min}^{-1}$. Dogs had their last injections of regular and NPH insulin 18 and $48 \mathrm{~h}$ respectively before the start of each study. Results are expressed as mean \pm SEM

ing unlabelled glucose) fell $(p<0.05)$ from $30.3 \pm 3.0$ to $0.0 \pm 2.5 \mu \mathrm{mol} \cdot \mathrm{kg}^{-1} \cdot \mathrm{min}^{-1}$ by $150 \mathrm{~min}$ and had risen to $25.8 \pm 6.8 \mu \mathrm{mol} \cdot \mathrm{kg}^{-1} \cdot \mathrm{min}^{-1} 30 \mathrm{~min}$ after glucagon replacement (Fig. 2, Table 1). When hepatic glucose production was estimated using ${ }^{3} \mathrm{H}$-3-glucose, glucose production by the liver was found to decrease ( $p<$ 0.05 ) from $44.9 \pm 9.6$ to $21.8 \pm 3.0 \mu \mathrm{mol} \cdot \mathrm{kg}^{-1} \cdot \mathrm{min}^{-1}$ by $150 \mathrm{~min}$ (Table 1). Use of the tracer method to estimate glucose production during glucagon replacement (150-300 min) was not valid since there was net output of ${ }^{3} \mathrm{H}$-glucose by the liver in this period (Table 1).

Peripheral glucose uptake as assessed using the non-radioactive $\mathrm{A}-\mathrm{V}$ difference approach fell from $30.6 \pm 2.8$ to $6.2 \pm 3.2 \mu \mathrm{mol} \cdot \mathrm{kg}^{-1} \cdot \mathrm{min}^{-1}$ by $150 \mathrm{~min}$ $(p<0.05)$ of insulin infusion but had risen to $19.3 \pm$ $4.9 \mu \mathrm{mol} \cdot \mathrm{kg}^{-1} \cdot \mathrm{min}^{-1} 30 \mathrm{~min}$ after glucagon replacement had begun (Fig. 2). However, hepatic glucose uptake as assessed from the net uptake of ${ }^{3} \mathrm{H}$-3-glucose, increased significantly $(p<0.05)$ from $4.3 \pm 4.1$ to $9.4 \pm 4.1 \mu \mathrm{mol} \cdot \mathrm{kg}^{-1} \cdot \mathrm{min}^{-1}$ during the insulin infusion (Table 1). Since there was net output of ${ }^{3} \mathrm{H}$-glucose from the liver during the glucagon replacement period (150- $300 \mathrm{~min}$ ), assessment of hepatic glucose uptake during that period was precluded. When peripheral and hepatic glucose uptake during the first period are added together to yield total glucose uptake it becomes evident that overall glucose uptake fell significantly $(p<0.05)$ from $34.6 \pm 3.5$ to $15.6 \pm 3.7 \mu \mathrm{mol} \cdot \mathrm{kg}^{-1}$. 


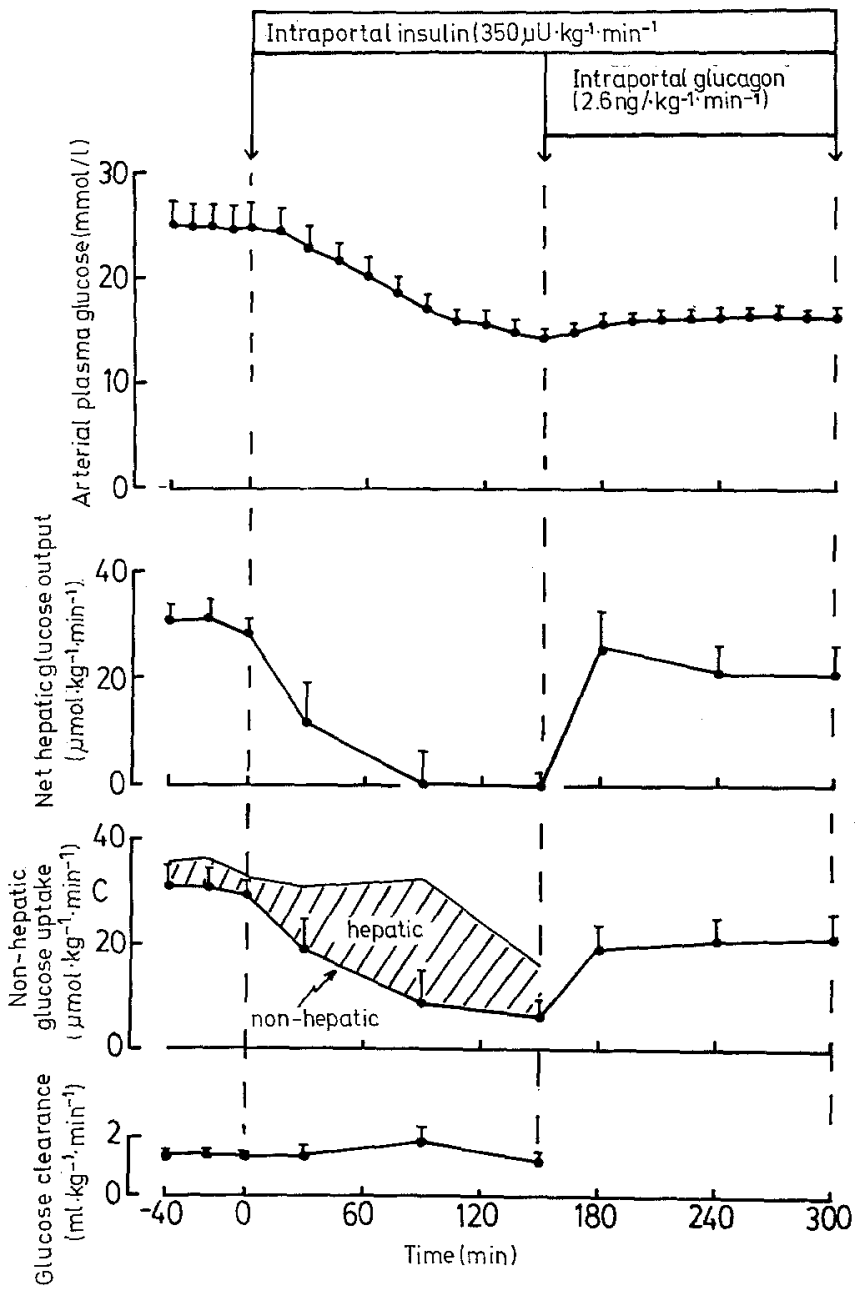

Fig. 2. Arterial plasma glucose levels, net hepatic glucose output, non-hepatic and hepatic (hatched area) uptake of glucose (see Materials and methods section for calculations), and glucose clearance in 7 pancreatectomised dogs during intraportal insulin infusion (350 $\left.\mu \mathrm{U} \cdot \mathrm{kg}^{-1} \cdot \mathrm{min}^{-1} ; 0-300 \mathrm{~min}\right)$, before $(0-150 \mathrm{~min})$ and during $(150-300 \mathrm{~min})$ intraportal replacement of glucagon at $2.6 \mathrm{ng} \cdot \mathrm{kg}^{-1}$. $\min ^{-1}$

$\min ^{-1}$ by $150 \mathrm{~min}$ of insulin infusion. Since the glucose level fell to a proportionately greater degree it is apparent that glucose clearance increased slightly in response to the infused insulin (Fig. 2).

Whole body glucose uptake was also assessed using tracer methods but only over the first $150 \mathrm{~min}$ for the reasons discussed above. Glucose utilisation $\left(\mathrm{R}_{\mathrm{d}}\right)$ fell from $45.5 \pm 9.2$ to $32.4 \pm 5.8 \mu \mathrm{mol} \cdot \mathrm{kg}^{-1} \cdot \mathrm{min}^{-1}$ by $150 \mathrm{~min}$ (Table 1). In line with this, glucose clearance rose from $1.76 \pm 0.19$ to $2.10 \pm 0.26 \mathrm{ml} \cdot \mathrm{kg}^{-1} \cdot \mathrm{min}^{-1}$ (Table 1). In the 4 dogs in which the experiment was terminated after $150 \mathrm{~min}$ of insulin infusion, hepatic glycogen contained $22.0 \pm 2.0 \%(31,248,000 \mathrm{dpm} /$ liver $)$ of the total amount of ${ }^{3} \mathrm{H}-3$-glucose that had been extracted by the liver during the $150 \mathrm{~min}$ of insulin infusion. This explains why there was net output of ${ }^{3} \mathrm{H}$-glucose by the liver during the glucagon replacement period as noted above.
Table 1. Glucose production assessed by tracer and arteriovenous (A-V) difference techniques, and tracer-determined glucose utilisation and glucose clearance in 7 pancreatectomised dogs during intraportal infusion at $350 \mu \mathrm{U} \cdot \mathrm{kg}^{-1} \cdot \mathrm{min}^{-1}$ for $300 \mathrm{~min}$. Net hepatic balance of ${ }^{3} \mathrm{H}$-glucose is also shown, and since there was mobilisation of labelled glycogen in the glucagon replacement period (150-300 $\mathrm{min}$ ), tracer-determined parameters are invalid in this period and are therefore not shown. The results are expressed as the mean values with one SEM depicted in parenthesis

\begin{tabular}{|c|c|c|c|c|c|}
\hline & \multirow[t]{2}{*}{ Method } & \multirow{2}{*}{$\begin{array}{l}\text { Controle } \\
\text { period }\end{array}$} & \multicolumn{3}{|c|}{ Time (min) } \\
\hline & & & $\begin{array}{l}135- \\
150^{c}\end{array}$ & 180 & $\begin{array}{l}270- \\
300^{c}\end{array}$ \\
\hline $\begin{array}{l}\text { Glucose pro- } \\
\text { duction }\end{array}$ & Tracer & $\begin{array}{l}44.9 \\
(9.6)\end{array}$ & $\begin{array}{l}21.8 \\
(3.0)\end{array}$ & $\begin{array}{l}31.1^{\mathrm{a}} \\
(2.3)\end{array}$ & $\begin{array}{l}24.1^{\mathrm{a}} \\
(1.2)\end{array}$ \\
\hline $\begin{array}{l}(\mu \mathrm{mol} \cdot \\
\left.\mathrm{kg}^{-1} \cdot \min ^{-1}\right)\end{array}$ & $A-V$ & $\begin{array}{l}30.3 \\
(3.0)\end{array}$ & $\begin{array}{c}0.0 \\
(2.5)\end{array}$ & $\begin{array}{l}25.8 \\
(6.8)\end{array}$ & $\begin{array}{l}21.0 \\
(5.3)\end{array}$ \\
\hline $\begin{array}{l}\text { Absolute He- } \\
\text { patic glucose } \\
\text { uptake } \\
\left(\mu \mathrm{mol} \cdot \mathrm{kg}^{-1} \text {. }\right. \\
\left.\min ^{-1}\right)\end{array}$ & $A-V$ & $\begin{array}{c}4.3 \\
(4.1)\end{array}$ & $\begin{array}{c}9.4 \\
(4.1)\end{array}$ & $-{ }^{\mathrm{b}}$ & $-{ }^{b}$ \\
\hline $\begin{array}{l}\text { Hepatic }{ }^{3} \mathrm{H}- \\
\text { glucose up- } \\
\text { take }[\mathrm{dpm}- \\
\left.\mathrm{kg}^{-1} \cdot \mathrm{min}^{-1}\right]\end{array}$ & $A-V$ & $\begin{array}{c}7,783 \\
(7,505)\end{array}$ & $\begin{array}{c}27,141 \\
(15,629)\end{array}$ & $\begin{array}{l}-6,904 \\
(7,645)\end{array}$ & $\begin{array}{r}-14,807 \\
(9,761)\end{array}$ \\
\hline $\begin{array}{l}\text { Glucose utili- } \\
\text { sation ( } \mu \mathrm{mol} \text {. } \\
\mathrm{kg}^{-1} \cdot \min ^{-1} \text { ) }\end{array}$ & Tracer & $\begin{array}{l}45.5 \\
(9.4)\end{array}$ & $\begin{array}{l}32.4 \\
(5.8)\end{array}$ & $-b$ & $-{ }^{b}$ \\
\hline $\begin{array}{l}\text { Glucose clear- } \\
\text { ance }(\mathrm{ml} \cdot \\
\left.\mathrm{kg}^{-1} \cdot \mathrm{min}^{-1}\right)\end{array}$ & Tracer & $\begin{array}{c}1.8 \\
(0.2)\end{array}$ & $\begin{array}{c}2.1 \\
(0.3)\end{array}$ & $-\mathrm{b}$ & $-b$ \\
\hline
\end{tabular}

a These numbers, although shown, are not valid due to the net efflux of ${ }^{3} \mathrm{H}$-glucose from the liver during this period. ${ }^{b}$ Cannot be calculated since the specific activity of liver glycogen at the designated time was not known. ${ }^{c}$ Average of all values obtained during this interval

\section{Gluconeogenic parameters}

The plasma alanine level rose progressively during the insulin infusion period, but decreased to below control levels when glucagon was replaced (Fig. 3). Hepatic alanine uptake $\left(4.04 \pm 0.72 \mu \mathrm{mol} \cdot \mathrm{kg}^{-1} \cdot \mathrm{min}^{-1}\right)$, on the other hand, did not change as the alanine rose and consequently the fractional extraction of alanine by the liver fell from $0.41 \pm 0.10$ to $0.24 \pm 0.06$. When glucagon was replaced the fractional extraction of alanine by the liver returned to $0.45 \pm 0.04$ and net hepatic uptake of alanine rose to $4.56 \pm 0.57 \mu \mathrm{mol} \cdot \mathrm{kg}^{-1} \cdot \mathrm{min}^{-1}$ (Fig. 3). The conversion of ${ }^{14} \mathrm{C}$-alanine to ${ }^{14} \mathrm{C}$-glucose fell by $83 \pm 14 \%(p<0.05)$ over the course of the first $150 \mathrm{~min}$ of insulin infusion (Fig. 4). Mobilisation of previously stored ${ }^{14} \mathrm{C}$-glucose would cause an overestimate of gluconeogenic conversion in the glucagon replacement period; thus these data were not calculated.

The arterial blood lactate level rose during the first $150 \mathrm{~min}$ of insulin infusion (from $0.80 \pm 0.15$ to $1.09 \pm$ $0.18 \mathrm{mmol} / \mathrm{l}$ ) but fell (to $0.68 \pm 0.12 \mathrm{mmol}$ ) when glucagon was replaced (Fig. 5). Uptake of lactate by the liver fell $(p<0.05)$ from $9.60 \pm 3.68$ to $1.09 \pm 1.25 \mu \mathrm{mol}$. $\mathrm{g}^{-1} \cdot \min ^{-1}$ by $150 \mathrm{~min}$ then rose to $9.76 \pm 4.65 \mu \mathrm{mol}$. 


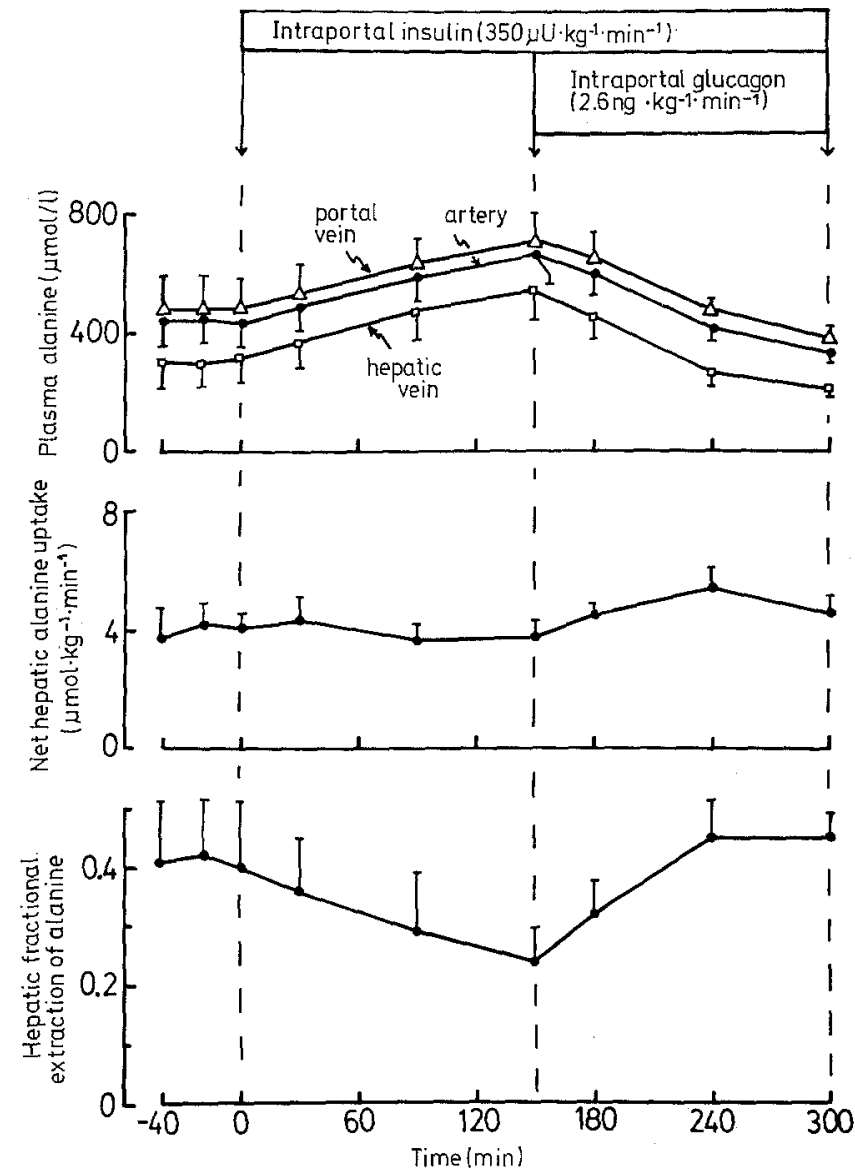

Fig.3. Arterial, portal vein and hepatic vein plasma concentrations of alanine, net hepatic uptake of alanine, and hepatic fractional extraction of alanine in 7 pancreatectomised dogs during intraportal infusion of insulin $\left(350 \mu \mathrm{U} \cdot \mathrm{kg}^{-1} \cdot \mathrm{min}^{-1} ; 0-300 \mathrm{~min}\right)$, before $(0-150 \mathrm{~min})$ and during $(150-300 \mathrm{~min})$ intraportal replacement of glucagon at $2.6 \mathrm{ng} \cdot \mathrm{kg}^{-1} \cdot \mathrm{min}^{-1}$

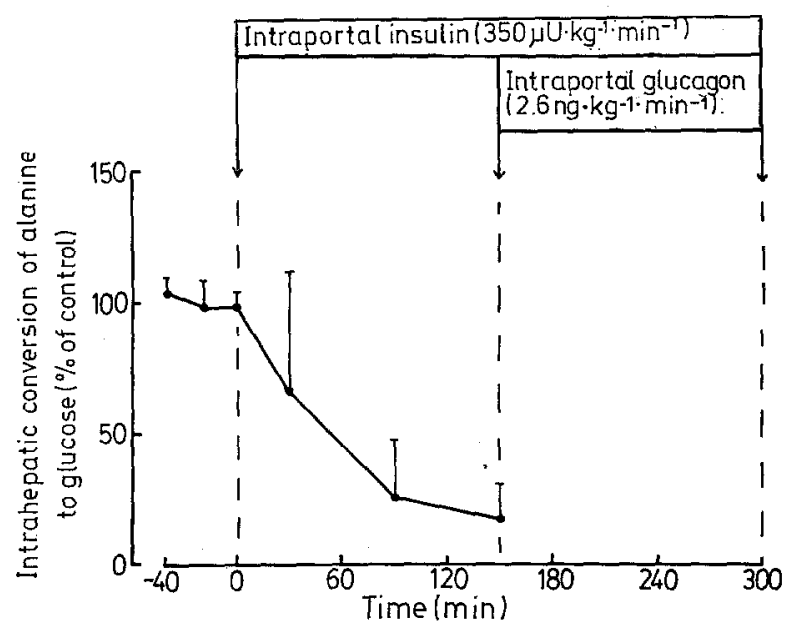

Fig.4. Conversion of ${ }^{14} \mathrm{C}$-alanine to ${ }^{14} \mathrm{C}$-glucose (expressed as a percentage of control values) during intraportal insulin infusion $\left(350 \mu \mathrm{U} \cdot \mathrm{kg}^{-1} \cdot \mathrm{min}^{-1} ; 0-150 \mathrm{~min}\right)$, before intraportal replacement of glucagon at $2.6 \mathrm{ng} \cdot \mathrm{kg}^{-1} \cdot \mathrm{min}^{-1}$

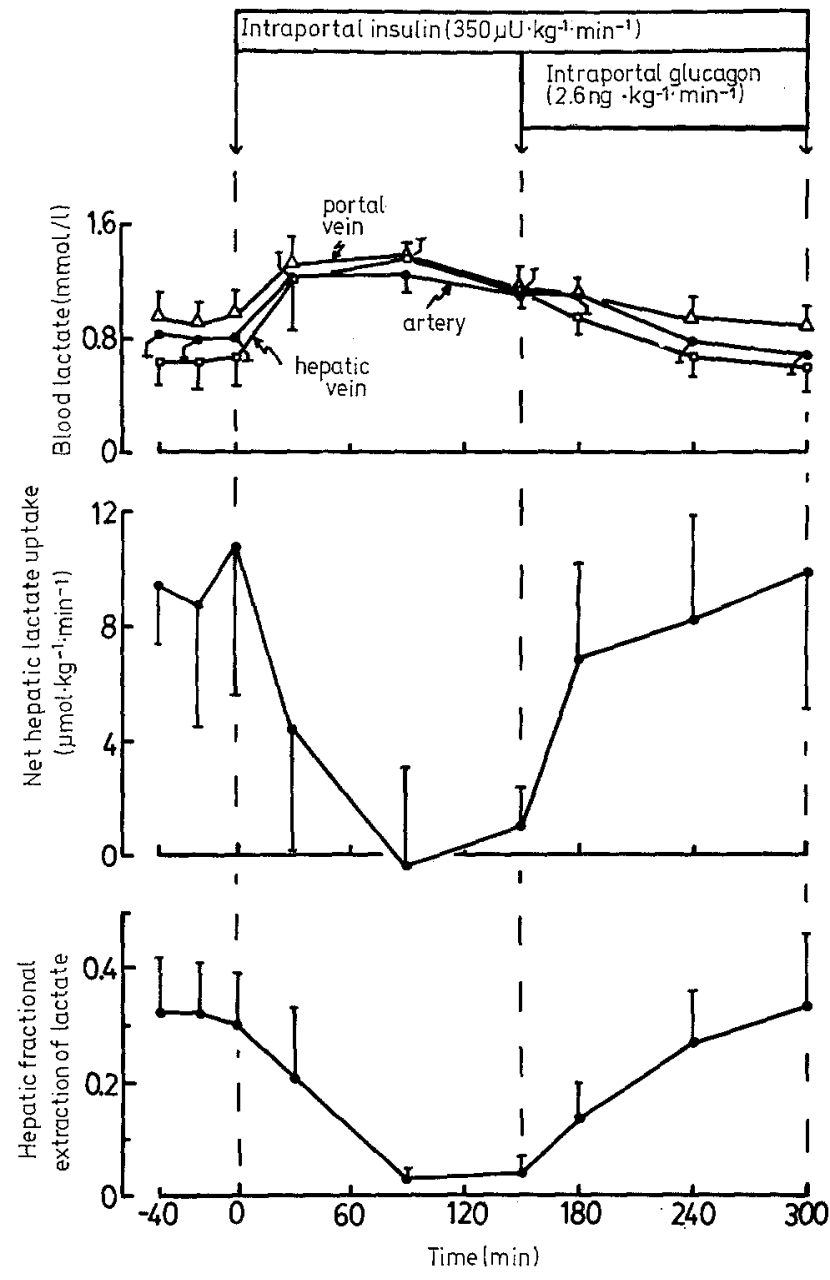

Fig.5. Blood lactate concentrations, net hepatic uptake of lactate and hepatic fractional extraction of lactate in 7 pancreatectomised dogs during intraportal infusion of insulin $\left(350 \mu \mathrm{U} \cdot \mathrm{kg}^{-1} \cdot \mathrm{min}^{-1}\right.$; $0-300 \mathrm{~min})$, before $(0-150 \mathrm{~min})$ and during (150-300 min) intraportal replacement of glucagon at $2.6 \mathrm{ng} \cdot \mathrm{kg}^{-1} \cdot \mathrm{min}^{-1}$

$\mathrm{kg}^{-1} \cdot \min ^{-1}$ by the end of the glucagon replacement period. Fractional extraction of lactate by the liver fell $(p<0.05)$ from $0.32 \pm 0.09$ to $0.04 \pm 0.03$ by $150 \mathrm{~min}$ and rebounded to $0.33 \pm 0.13$ by $300 \mathrm{~min}$ (Fig. 5).

The arterial blood glycerol concentration fell from $432 \pm 108$ to $278 \pm 113 \mu \mathrm{mol} / \mathrm{l}$ over the course of the first $150 \mathrm{~min}$ of insulin infusion and remained at this level when glucagon was replaced (Fig.6). The net uptake of glycerol by the liver fell from $13.4 \pm 5.2$ to $6.9 \pm 3.0 \mu \mathrm{mol} \cdot \mathrm{kg}^{-1} \cdot \mathrm{min}^{-1}$ by $150 \mathrm{~min}$ and remained at that rate when glucagon was replaced. Fractional extraction of glycerol by the liver $(0.73 \pm 0.05)$ remained unchanged throughout the entire study (Fig.6).

\section{Plasma non-esterified fatty acids (NEFA)}

The arterial plasma NEFA concentration fell $(p<0.05)$ from $3.34 \pm 0.31$ to $1.66 \pm 0.20 \mathrm{mmol} / 1$ by $150 \mathrm{~min}$ and remained at this level when glucagon was replaced 


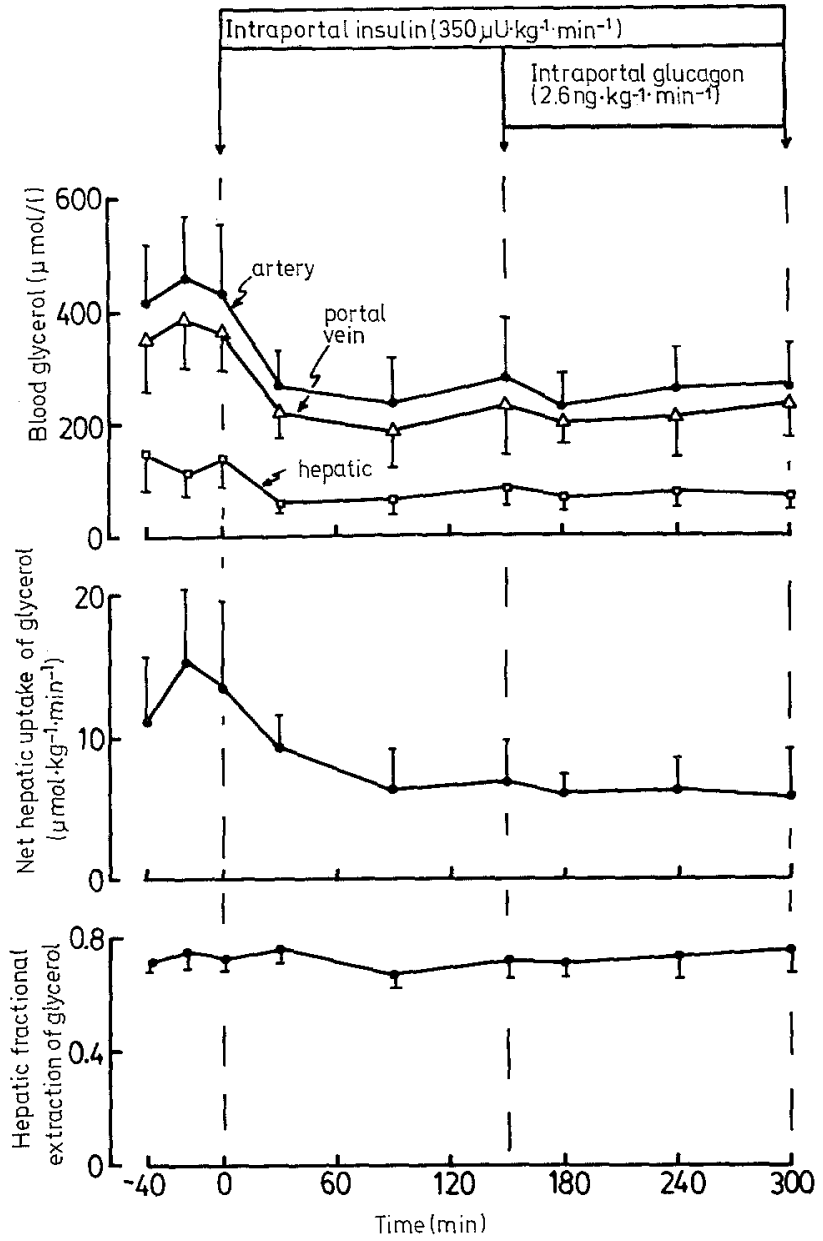

Fig.6. Blood glycerol concentrations, net hepatic uptake of glycerol and hepatic fractional extraction of glycerol in 7 pancreatectomised dogs during intraportal infusion of insulin $\left(350 \mu \mathrm{U} \cdot \mathrm{kg}^{-1} \cdot \mathrm{min}^{-1}\right.$; $0-300 \mathrm{~min})$, before $(0-150 \mathrm{~min})$ and during $(150-300 \mathrm{~min})$ intraportal replacement of glucagon at $2.6 \mathrm{ng} \cdot \mathrm{kg}^{-1} \cdot \mathrm{min}^{-1}$

(Fig. 7). Hepatic uptake of NEFA and hepatic fractional extraction of NEFA fell from $13.6 \pm 2.7$ to $3.2 \pm$ $1.9 \mu \mathrm{mol} \cdot \mathrm{kg}^{-1} \cdot \mathrm{min}^{-1}(p<0.05)$ and from $0.20 \pm 0.08$ to $0.11 \pm 0.09$ (NS), respectively, by $150 \mathrm{~min}$ and rebounded to $10.0 \pm 3.8 \mu \mathrm{mol} \cdot \mathrm{kg}^{-1} \cdot \mathrm{min}^{-1}$ and $0.21 \pm$ 0.06 respectively by the end of the glucagon replacement period.

\section{Discussion}

The intraportal infusion of insulin reduced both the hyperglucagonaemia and hyperglycaemia evident in the untreated conscious pancreatectomised dog. This confirms earlier observations in both the diabetic dog $[4,5]$ and man $[6,7]$. In the present study, the abnormally high net hepatic glucose output was reduced to zero by insulin infusion at $350 \mu \mathrm{U} \cdot \mathrm{kg}^{-1} \cdot \mathrm{min}^{-1}$, a rate slightly below that $\left(420 \mu \mathrm{U} \cdot \mathrm{kg}^{-1} \cdot \mathrm{min}^{-1}\right)$ necessary to maintain euglycaemia in pancreatectomised dogs (Stevenson and Cherrington, unpublished observations).

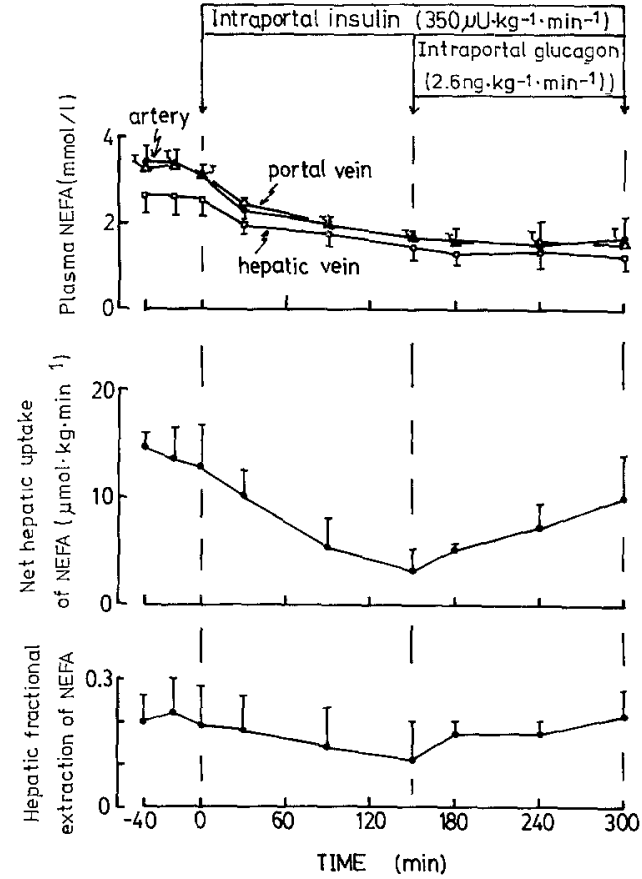

Fig. 7. Plasma non-esterified fatty acid (NEFA) concentrations, net hepatic uptake of NEFA and hepatic fractional extraction of NEFA in 7 pancreatectomised dogs during intraportal infusion of insulin $\left(350 \mu \mathrm{U} \cdot \mathrm{kg}^{-1} \cdot \min ^{-1} ; 0-300 \mathrm{~min}\right)$, before $(0-150 \mathrm{~min})$ and during (150-300 min) intraportal replacement of glucagon at $2.6 \mathrm{ng} \cdot \mathrm{kg}^{-1}$. $\min ^{-1}$

Surprisingly it was the fall in glucose output, rather than an increase in glucose utilisation, which caused the glucose level to fall.

The glucose production rate was considerably lower when assessed using the A-V difference technique with unlabelled substrate than when measured using the tracer technique with ${ }^{3} \mathrm{H}-3$-glucose although the latter also indicated a substantial insulin induced drop in glucose supply (Table 1). In the control period, the difference between the two methods was 14.6 umol . $\mathrm{kg}^{-1} \cdot \mathrm{min}^{-1}$. Part of this difference can be explained by the movement of glucose into the liver as indicated by the net uptake of ${ }^{3} \mathrm{H}-3$-glucose $\left(4.3 \mu \mathrm{mol} \cdot \mathrm{kg}^{-1}\right.$. $\mathrm{min}^{-1}$ ) (Table 1). The remaining discrepancy may be explained by the fact that the tracer method measures any non-hepatic glucose production (i.e. renal gluconeogenesis), the possibility that ${ }^{3} \mathrm{H}-3$-glucose may undergo futile cycling within the liver thereby losing its label and giving rise to an overestimate of $R_{a}$ [36], and the possibility that net glucose balance measured by our methods may underestimate the true net glucose production rate. The difference in the two methods was magnified in the insulin infusion period $\left(21.8 \mu \mathrm{mol} \cdot \mathrm{kg}^{-1} \cdot \mathrm{min}^{-1}\right)$ as a result of a higher rate of glucose uptake by the liver $\left(9.4 \mu \mathrm{mol} \cdot \mathrm{kg}^{-1} \cdot \mathrm{min}^{-1}\right)$ (Table 1). The latter would affect measurement of net hepatic glucose production as calculated by the arteriovenous technique but not $R_{a}$ as determined by the tracer method. 
The insulin-induced fall in hepatic glucose production was evident using either method of measuring glucose production and could be the result of a reduction in hepatic glycogenolysis and/or gluconeogenesis. An estimate of the possible contribution of gluconeogenesis to overall glucose production can be obtained by calculating the hepatic uptake of gluconeogenic precursors before and during infusion of insulin. If one assumes that uptake of pyruvate by the liver is onetenth that of lactate and that the uptake of alanine equals the uptake of the other gluconeogenic amino acids combined [37], then total gluconeogenic precursor uptake in the control period would have approximated $32 \mu \mathrm{mol} \cdot \mathrm{kg}^{-1} \cdot \mathrm{min}^{-1}$. Since gluconeogenic efficiency (the fraction of extracted ${ }^{14} \mathrm{C}$-alanine converted to circulating ${ }^{14} \mathrm{C}$-glucose) was 0.53 in that period, gluconeogenesis must have accounted for a minimum of $8.5 \mu \mathrm{mol} \cdot \mathrm{kg}^{-1} \cdot \mathrm{min}^{-1}$ (i. e. $28 \%$ of net hepatic glucose output) and a maximum (i. e. assuming an efficiency of 1.0) of $17 \mu \mathrm{mol} \cdot \mathrm{kg}^{-1} \cdot \mathrm{min}^{-1}$ of glucose (i.e. $56 \%$ of the net hepatic glucose output). It appears, therefore, that about one-quarter to one-half of glucose production was derived from gluconeogenesis and one-half to three-quarters was attributable to glycogenolysis. By 150 min of insulin infusion, net glucose output by the liver was almost completely shut off while net hepatic uptake of gluconeogenic substrates was $7.8 \mu \mathrm{mol}$. $\mathrm{kg}^{-1} \cdot \min ^{-1}$. Since gluconeogenic efficiency was zero, the precursors still being extracted were presumably either being oxidised or converted to glucose-6-phosphate and stored in glycogen. The accumulation of ${ }^{14} \mathrm{C}$ glucose in liver glycogen confirms the latter alternative. On longer exposure to insulin, gluconeogenesis was therefore markedly, although not completely, inhibited with its product being stored in glycogen rather than released from the liver. In addition glycogenolysis was substantially reduced perhaps by as much as $100 \%$.

When the fall in plasma glucagon caused by insulin infusion was reversed by the intraportal replacement of glucagon, net hepatic glucose output (assessed using unlabelled glucose) was restored to about $70 \%$ of the starting value (Fig.2). As a result, the fall in plasma glucose was arrested and indeed glucose rose slightly. During the glucagon replacement period, net hepatic uptake of ${ }^{3} \mathrm{H}$-3-glucose ceased and net output of ${ }^{3} \mathrm{H}$ glucose began (Table 1), presumably as a result of glucagon stimulated breakdown of the labelled glycogen that had accumulated during the first $150 \mathrm{~min}$ of insulin infusion. For this reason tracer determined glucose production was inaccurate and markedly underestimated the rebound in glucose production.

From the A-V difference data with unlabelled substrates, it can be concluded that the indirect effect of insulin, e.g. the fall in glucagon, contributed more to the fall in glucose production, both glycogenolysis and gluconeogenesis, than did the direct effect of basal insulin concentrations per se. This confirms previous observations that glucagon can affect both glycogenolysis and gluconeogenesis in vivo $[9,11,13,21,29]$ and indeed supports the proposal by Unger and Orci [42] that glucagon is the principal mediator of the endogenous hyperglycaemia of diabetes. When glucagon was replaced, net hepatic glucose output increased from 0 to $25.8 \mu \mathrm{mol} \cdot \mathrm{kg}^{-1} \cdot \mathrm{min}^{-1}$ by $30 \mathrm{~min}$ and the uptake of the gluconeogenic substrates was almost restored $\left(23 \mu \mathrm{mol} \cdot \mathrm{kg}^{-1} \cdot \mathrm{min}^{-1}\right)$ to the rate evident in the control period. Gluconeogenic efficiency could not be estimated during the glucagon replacement period, however, due to release of ${ }^{14} \mathrm{C}$-glucose from labelled glycogen (data not shown). If the gluconeogenic efficiency measured in the control period was re-established by restoring the basal glucagon level, then the minimum contribution of gluconeogenesis to glucose production would have been approximately $23 \%$. These data indicate that the abnormal rates of the two processes were indeed related to the presence of excess glucagon in the uncontrolled diabetic state.

When one considers the gluconeogenic substrates, it is apparent that during insulin infusion lactate uptake by the liver was virtually shut off, the fractional extraction falling from $0.32 \pm 0.09$ to $0.04 \pm 0.03$. As a result there was a marked increase in the blood lactate concentration. Lactate metabolism returned to its starting state when the glucagon was replaced, suggesting that the initial changes were due mainly to the fall in glucagon, i.e. an indirect effect of insulin. Therefore, although basal insulin concentrations have been shown to directly inhibit gluconeogenesis in vivo and specifically to inhibit lactate release from peripheral tissues [34], the changes in lactate metabolism observed during insulin infusion in the diabetic dog could be attributed mainly to the reduction in hyperglucagonaemia. Since glucagon is known to stimulate gluconeogenesis by an intrahepatic action $[11,21,29]$ and since lactate uptake into the liver cell is not thought to be under hormonal control, the changes in hepatic uptake of lactate may be related to changes in passive diffusion of lactate across the liver cell membrane due to an increase and decrease in intracellular pyruvate concentrations, respectively, during the fall and rise in glucagon levels.

This theory would also explain why the fractional extraction of alanine by the liver decreased when the glucagon concentration decreased and returned to starting levels when glucagon was replaced. However, glucagon has also been shown to affect amino acid transport across the liver cell membrane both in vivo $[11,21,29,30]$ and in vitro [31-34], thus at least part of the change in the hepatic fractional extraction of alanine may have been related to changes in alanine transport. Since the plasma alanine concentration rose by about $50 \%$, despite little change in alanine uptake by the liver, alanine release from peripheral tissues must have increased. Glucagon is thought to have little effect on peripheral gluconeogenic substrate supply [34], so it seems likely that the increased alanine release was due to insulin's action. Indeed, hyperglycaemia in 
the presence of basal insulin and glucagon concentrations has been shown to increase alanine production by peripheral tissues [35].

Re-establishing hyperglucagonaemia during insulin infusion had no effect on glycerol metabolism unlike the effects observed on the other two gluconeogenic substrates described above. In this case, insulin infusion decreased blood glycerol levels presumably due to inhibition of lipolysis and this effect was maintained when glucagon was replaced. Since the fractional extraction of glycerol by the liver remained unchanged throughout the study, hepatic uptake of glycerol fell by about $50 \%$ and remained suppressed. This observation may explain in part why glucagon replacement restored hepatic glucose production to only $70 \%$ of its initial value (i.e. gluconeogenesis from glycerol remained depressed).

Inhibition of lipolysis by insulin not only caused a decrease in the blood glycerol level but also in plasma NEFA concentrations. This resulted in a decrease in hepatic uptake of NEFA. However, the decrease in uptake was exaggerated by a decrease in fractional extraction of NEFA by the liver. This latter effect seems to be related to the fall in glucagon levels, since glucagon replacement resulted in partial restoration of hepatic NEFA uptake and re-establishment of the initial fractional extraction of NEFA by the liver. Since it is generally believed that movement of NEFA into the liver cell is not under hormonal control, the changes in NEFA fractional extraction must be related to glucagon's intrahepatic action. Stimulation of gluconeogenesis by glucagon would presumably increase the flux from pyruvate to glucose, thus perhaps in turn increasing the flux from other substrates such as lactate and oxaloacetate to pyruvate. The resulting decrease in concentration of (TCA) cycle intermediates would presumably result in increased flux of NEFA to the TCA cycle and thus increase uptake of NEFA by the liver more than would be predicted from the load of NEFA delivered to the liver. Thus a decrease in gluconeogenic stimulation due to a fall in glucagon concentration might result in decreased fractional extraction of NEFA by the liver, an effect that would be reversed as the initial hyperglucagonaemia was re-established.

Another action normally attributed to insulin is an increase in glucose clearance. When glucose clearance was calculated using the A-V difference or tracer method, it was apparent that during the control period glucose clearance was depressed below normal, confirming earlier results in diabetic dogs $[26,27]$, and that it increased slightly during insulin infusion. Under normal conditions the brain accounts for about $80 \%$ of total glucose uptake [28]. When basal insulin levels were re-established in diabetic dogs withdrawn from insulin therefore, only a small increase in glucose clearance would be predicted and this was the case. However, glucose clearance tends to increase as plasma glucose concentrations decrease though the effect is more pro- nounced in man (40) than in the dog (41). It is conceivable, therefore, that the small increase in glucose clearance in the present study was purely a function of the fall in plasma glucose.

It thus appears that the fall in glucagon concentration can explain the majority of responses, especially with respect to hepatic handling of gluconeogenic substrates, resulting from insulin infusion to conscious pancreatectomised dogs that had had insulin withdrawn at least $18 \mathrm{~h}$ previously. It should also be noted that interpretation of the above results would have been markedly different if $\mathrm{A}-\mathrm{V}$ difference techniques using unlabelled substrates had not been used thus illustrating a consequence of violating a basic assumption of the tracer technique.

Acknowledgements. RWS was supported by a JDF Career Development award. The authors are grateful for the skilled technical assistance of L. Brown, P. Donahue and J. Hastings. Supported by NIH grant AM18243-12 and the DRTC grant 5 P60 AM20593.

\section{References}

1. Unger RH, Lefebvre PJ (1972) Glucagon physiology. In: Lefebvre PJ, Unger RH (eds) Glucagon, Molecular Physiology, Clinical and Therapeutic Implications. Pergamon Press, London New York, pp 213-244

2. Unger RH, Orci L (1977) Role of glucagon in diabetes. Arch Intern Med 137: 482-491

3. Lilavivathana V, Brodows RG, Woolf PD, Campbell RG (1979) Counterregulatory hormonal responses to rapid glucose lowering in diabetic man. Diabetes 28: 873-877

4. Stevenson RW, Orskov H, Parsons JA, Alberti KGMM (1983) Metabolic responses to intraduodenal glucose loading in insulininfused diabetic dogs. Am J Physiol 245: E 200-E208

5. Stevenson RW, Parsons JA, Alberti KGMM (1981) Comparison of the metabolic responses to portal and peripheral infusions of insulin in diabetic dogs. Metabolism 30: 745-752

6. Raskin P, Unger RH (1978) Hyperglucagonemia and its suppression: importance in the metabolic control of diabetes. $N$ Engl $J$ Med 299: 433-436

7. Raskin P, Pietri A, Unger R (1979) Changes in glucagon levels after four to five weeks of glucoregulation by portable insulin infusion pump. Diabetes 28: 1033-1035

8. Cherrington AD, Steiner KE (1982) The effects of insulin on carbohydrate metabolism in vivo. Clin Endocrinol Metab 11: 307-328

9. Jennings AS, Cherrington AD, Liljenquist JE, Keller U, Lacy WW, Chiasson JL (1977) The roles of insulin and glucagon in the regulation of gluconeogenesis in the postabsorptive dog. Diabetes $26: 847-856$

10. Rappaport AM, Vranic M, Wrenshall GA (1966) A pedunculated subcutaneous autotransplant of an isolated pancreas remnant, for the temporary deprivation of internal pancreatic secretion in the dog. Surgery 59: 792-798

11. Chiasson J-L, Liljenquist JE, Sinclair-Smith BC, Lacy WW (1975) Gluconeogenesis from alanine in normal postabsorptive man: intrahepatic stimulatory effect of glucagon. Diabetes 24: 574-584

12. Goresky CA, Back GG, Nadeau BE (1975) Red cell carriage of label: its limiting effect on the exchange of materials in the liver. Circ Res 36: 328-351

13. Cherrington AD, Chiasson $J-L$, Liljenquist JE, Jennings AS, Keller U, Lacy WW (1976) The role of insulin and glucagon in the regulation of basal glucose production in the postabsorptive dog. J Clin Invest 58: 1407-1418 
14. Cherrington AD, Lacy WW, Chiasson J-L (1978) Effect of glucagon on glucose production during insulin deficiency in the dog. J Clin Invest 62: 664 677

15. Aguilar-Parada E, Eisentraut AM, Unger RH (1969) Pancreatic glucagon secretion in normal and diabetic subjects. Am J Med Sci 257: 415-419

16. Wide L, Porath J (1966) Radioimmunoassay of proteins with the use of sephadex-coupled antibodies. Biochim Biophys Acta 130: 257-260

17. Wall JS, Steele R, DeBodo RC, Altszuler N (1957) Effect of insulin on utilization and production of circulating glucose. Am J Physiol 189: 43-50

18. DeBodo RD, Steele R, Altszuler N, Dunn A, Bishop JS (1963) On the hormonal regulation of carbohydrate metabolism: studies with ${ }^{14} \mathrm{C}$-glucose. Recent Prog Horm Res 19: 445-448

19. Cherrington AD, Vranic M (1973) Effect of arginine on glucose turnover and plasma free fatty acids in normal dogs. Diabetes 22: $537-543$

20. Chiasson J-L, Liljenquist JE, Jennings AS, Lacy WW, Cherrington AD (1977) Gluconeogenesis: methodological approaches in vivo. Fed Proc 36: 230-235

21. Cherrington AD, Williams PE, Shulman GI, Lacy WW (1981) Differential time course of glucagon's effect on glycogenolysis and gluconeogenesis in the conscious dog. Diabetes 30:180-187

22. Hetenyi G Jr (1981) Calculation of the rate of gluconeogenesis in vivo. In: Cobelli C, Bergman RN (eds) Carbohydrate Metabolism. John Wiley and Sons Ltd, pp 201-219

23. Leevy CM, Mendenhall CL, Lesko W, Howard MM (1962) Estimation of hepatic blood flow with indocyanine green. J Clin Invest 71: $1169-1179$

24. Greenway CV, Stark RD (1971) Hepatic vascular bed. Physiol $\operatorname{Rev} 51: 23-65$

25. Chan T, Exton J (1976) A rapid method for the determination of glycogen content and radioactivity in small quantities of tissue or isolated hepatocytes. Anal Biochem 71: 96-105

26. Perez G, Kemmer FW, Lickley HLA, Vranic M (1981) Importance of glucagon in mediating epinephrine-induced hyperglycemia in alloxan-diabetic dogs. Am J Physiol 241: E328-E335

27. Stevenson RW, Parsons JA, Alberti KGMM (1983) Effect of intraportal and peripheral insulin on glucose turnover and recycling in diabetic dogs. Am J Physiol 244: E190-E195

28. Cahill GF Jr (1971) Physiology of insulin in man. Diabetes 20: 785-799

29. Davis MA, Williams PE, Cherrington AD (1985) Effect of glucagon on hepatic lactate metabolism in the conscious dog. Am J Physiol 248: E463-E470

30. Brockman RP, Bergman EN, Joo PK, Manns JG (1975) Effect of glucagon and insulin on net hepatic metabolism of glucose precursors in sheep. Am J Physiol 229: 1344-1350
31. Le Cam A, Freychet P (1976) Glucagon stimulates the A system for neutral amino acid transport in isolated hepatocytes of adult rat. Biochem Biophys Res Commun 72: 893-901

32. Kilberg MS, Neuhaus OW (1977) Hormonal regulation of hepatic amino acid transport. J Supramol Struct 6: 191-204

33. Kilberg MS, Handlogten ME, Christensen HN (1980) Characteristics of an amino acid transport system in rat liver for glutamine, asparagine, histidine, and closely related analogs. J Biol Chem 255: 4011-4019

34. Cherrington AD (1982) Gluconeogenesis: its regulation by insulin and glucagon. In: Brownlee M (ed) Handbook of Diabetes Mellitus, Ch 2. Garland STPM Press, New York, pp 45-119

35. Shulman GI, Lacy WW, Liljenquist JE, Keller U, Williams PE, Cherrington $\mathrm{AD}$ (1980) Effect of glucose, independent of changes in insulin and glucagon secretion, on alanine metabolism in the conscious dog. J Clin Invest 65: 496-505

36. Katz J, Rognstad R (1976) Futile cycles in the metabolism of glucose. Curr Top Cell Regul 10: 237-289

37. Diamond MP, Rollings RC, Erlendson L, Williams PE, Lacy WW, Rabin D, Cherrington AD (1980) Dichloroacetate - its in vivo effects on carbohydrate metabolism in the conscious dog. Diabetes 29: 702-710

38. Lloyd B, Burrin J, Smythe P, Alberti KGMM (1978) Enzymic fluorometric continuous-flow assays for blood glucose, lactate, pyruvate, alanine, glycerol, and 3-hydroxybutyrate. Clin Chem 24: 1724-1729

39. Ho RJ (1970) Radiochemical assay of long chain fatty acids using ${ }^{63} \mathrm{Ni}$ as tracer. Anal Biochem 26:105-113

40. Gottesman I, Mandarino L, Gerich J (1984) Review: use of glucose uptake and glucose clearance for the evaluation of insulin action in vivo. Diabetes 33: 184-191

41. Cherrington AD, Williams PE, Harris MS (1978) Relationship between the plasma glucose level and glucose uptake in the conscious dog. Metabolism 27: 787-791

42. Unger, RH, Groi L (1975) The essential role of glucagon in the pathogenesis of the endogenous hypoglycaemia of diabetes mellitus. Lancet 1: 14-16

Received: 10 February 1987

and in revised form: 1 May 1987

Dr. Alan D. Cherrington, Ph. D.

Department of Molecular Physiology and Biophysics

Vanderbilt University School of Medicine

Nashville, Tennessee 37232

USA 